\title{
Karakteristik Ibu Melahirkan Sectio Caesaria Peserta Jaminan Kesehatan Nasional di Rumah Sakit Profit X di Sekitar Jakarta
}

\author{
Analysis of Sectio Caesaria Characteristics at Profit Hospital X around Jakarta \\ under National Health Insurance
}

\author{
Trisna Budy Widjayanti $\mathrm{i}^{*}$ \\ ${ }^{a}{ }^{*}$ Universitas Mohammad Husni Thamrin Jalan Raya Pondok Gede Kramat Jati Jakarta Timur 13550, Indonesia
}

\section{A B S T R A K}

Program Jaminan Kesehatan Nasional (JKN) memudahkan akses ibu melahirkan Sectio Caesaria (SC) di RS. Dalam tahun 20142017 persalinan SC menempati urutan 10 jumlah kasus dan klaim tertinggi. WHO menetapkan angka optimum SC sebesar $15 \%$ sebagai salah satu standar kualitas pelayanan persalinan ibu. Tujuan penelitian ini untukmengidentifikasi karakteristik sosial ekonomi dan klinis dari ibu yang melahirkan SC yang berhubungan dengan penggunaan JKN di Rumah Sakit Profit (RSP) X di sekitar Jakarta. Penelitian menggunakan desain Cross Sectional dengan total sampel sebanyak 385 ibu melahirkan SC yang diambil dari rekam medis pada periode januari 1- 31 Desember 2018. Karakteristik sosial ekonomi dan klinis Ibu melahirkan SC sebagai variabel independen dan penggunaan JKNsebagai variabel dependen Dilakukan analisisdeskriptif untuk menggambarkan distribusi frekwensi dari variabel-variabel yang diteliti dan analisis regressi logistik digunakan untuk menguji hubunagn antara variabel independen dan dependen..Hasil penelitianmenunjukkan bahwa ibu melahirkan SC di RSP sebesar $71.29 \%$ dari total persalinan dan79\%nya adalah peserta JKN.Hasil uji statistik menunjukan bahwa terdapat hubunganyang signifikan antara kasus rujukan $(\mathrm{p}=0.002 ; \mathrm{OR}=2.320)$; usia ibu $(\mathrm{p}=0.010 ; 0 \mathrm{R}=2,574)$, dan penyakit penyerta $(\mathrm{p}=0.001$; $\mathrm{OR}=2.761$ ) denganpenggunaan JKN pada ibu-ibu yang melahirkan dengan SC

Kata kunci: Karakteristik Sosial Ekonomi dan Klinis, Sectio Caesaria, Jaminan Kesehatan Nasional

\section{Pendahuluan}

Pelayanan persalinan di RS pada tiga tahun berturut turut sejak program JKN diluncurkan menunjukkan klaim kasus dan biaya tertinggi. Rata rata $55 \%$ dari total persalinan adalah persalinan SC. Total biaya persalinan SC selalu menempati urutan teratas dalam sebaran klaim Indonesian Case Base Groups(INA-CBGs) sejak 2014 s/d 2017. ${ }^{1}$ Proporsi angka kejadian persalinan SC di Indonesia terus meningkat baik di rumah sakit pemerintah maupun swasta. ${ }^{2}$ WHO menetapkan standar rata-rata SC untuk seluruh negara sebesar $10-15 \%$ per total persalinan, sementara itu di rumah sakit pemerintah rata-rata $11 \%$ dan di rumah sakit swasta lebih dari $30 \%{ }^{3}$.

Peningkatan angka SC pada Data Survey Demografi dan Kesehatan di tahun 2012 ke 2017 juga

\section{A B S T R A C T}

The National Health Insurance Program (JKN) facilitates access to mothers giving birth to Caesaria (SC) in hospitals. In year 2014-2017, SC deliveries ranked $10^{\text {th }}$ in the number of cases and had the highest JKN claims. WHO set the optimumSC rate of $15 \%$ as one of the quality standards for maternity services. The purpose of the study was to identify the socioeconomic and clinical characteristic of mothers giving birth to SC related to JKN use. in the Profit Hospital (RSP) X near Jakarta. The study used a crosssectional design with a total sample of 385 mothers with SC deliveries taken from medical records in the January 1-31 December 2018 period. Socioeconomic and clinical characteristics as the independent variables and Health Insurance use as the dependent variable. Descriptive analysis was performed to describe the frequency distribution of the studied variables and logistic rgression analysis was used to examine the association between the independent and the dependent variables. The results showed that mothers gave birth to SC in RSP were $71.29 \%$ of the total deliveries with $79 \%$ were JKN users. Statistical test results showed a significant relationship between variables of referral case $(\mathrm{p}=0.002 ; 0 \mathrm{R}=2.320)$; mothers' age $(\mathrm{p}=0.010$; $\mathrm{OR}=2,574)$, and maternal comorbidities $(\mathrm{p}=0.001 ; \mathrm{OR}=2.761)$ with the Health Insurance use in mothers giving birth to SC.

Key words: Socio-Economic and Clinical Characteristics, Sectio Caesaria, National Health Insurance menunjukan peningkatan angka dari $7 \%$ menjadi $17 \%$ dari total persalinan ${ }^{4}$. Proporsi persalinan SC tertinggi di Provinsi DKI Jakarta ${ }^{5}$. Program JKN memberikan kemudahan akses pelayanan pada Ibu melahirkan di RSP X. Tindakan persalinan SC yang terus meningkat memerlukan perhatian sebagai kendali mutu dan kendali biaya dalam pelaksanaan JKN. Berdasarkan uraian di atas penelitian ini bertujuan untuk melihat gambaran dan membandingkan faktor faktor sosial ekonomi dan klinis Ibu melahirkan SC antara peserta JKN dan Non JKN di RS Profit (RSP) yang telah bekerjasama dengan JKN. Hal ini dapat sebagai masukan perbaikan implementasi kebijakan Jaminan Kesehatan Nasional terkait pelayanan kesehatan ibu dan anak.

*Korespondensi: Trisna Budy Widjayanti, Universitas Mohammad Husni Thamrin Jalan Raya Pondok Gede Kramat Jati Jakarta Timur 13550, Indonesia. Email: trisna.widjayanti@gmail.com 


\section{Metodologi}

Populasi penelitian ini adalah seluruh ibu yang melahirkan SC periode 1 Januari sampai 31 Desember 2018 sebanyak 529 yang memiliki dokumen rekam medis di rumah sakit studi penelitian. Kriteria inklusi yaitu ibu melahirkan SC yang tercatat dalam rekam medis RS. Kriteria eksklusi rekam medis yang tidak dapat terbaca dengan jelas. Pengambilan sampel dilakukan dengan menggunakan metode Proporsional Simple Random Sampling dimana sampling frame semua populasi ibu yang melahirkan SC sesuai kriteria inklusi. Pemilihan secara random menggunakan program excel sebanyak 385 rekam medis ibu melahirkan SC.

Desain penelitian Cross Sectional. Variabel karakteristik sosial ekonomi ibu melahirkan SC yaitu jaminan kesehatan, kelas rawat, rujukan, pendidikan, pekerjaan dan suku ibu melahirkan SC yang tercatat dalam rekam medis. Variabel klinis terdiri jenis SC, usia ibu, usia kehamilan, paritas, riwayat Antenatal Care (ANC), kondisi bentuk panggul (pelvic) dan plasenta, penyakit penyerta dan posisi janin dalam rahim ibu melahirkan SC yang tercatat dalam rekam medis. Variabel karakteristik sosial ekonomi dan klinis Ibu melahirkan SC sebagai variabel independen dan Jaminan Kesehatan sebagai variabel dependen.

Analisa data univariat, analisis bivariat Chi Square dan multivariat dengan regresi logistik digunakan untuk mengetahui faktor faktor yang berpengaruh pada Ibu yang melahirkan SC dengan Jaminan Kesehatan. Data diolah menggunakan software Spss versi 22 .

Instrumen kuesioner checklist penelitian berdasarkan catatan rekam medik yang merupakan alat standar assesmen sebelum dilakukan persalinan SC di RS. Checklist kuesioner dicobakan untuk diisi berdasarkan data rekam medis RS oleh enumerator. Hasilnya terdapat kesesuaian seluruh variabel pada kuesioner checklist penelitian dengan data pada rekam medis. Enumerator rekam medis terdiri dari tenaga bidan dan manajemen RS berpendidikan D3. Pengumpulan data dilakukan melalui tahapan antara lain: pelatihan enumerator, dilanjutkan dengan pengisian instrument check list penelitian oleh enumerator.

Penelitian ini telah melalui prosedur kaji etik oleh Komisi Etik Riset dan Pengabdian Kesehatan Masyarakat Fakultas Kesehatan Masyarakat Universitas Indonesia. Penelitian ini dinyatakan lolos dan layak untuk dilaksanakan dengan No: Ket-489/ UN2.F10/PPM.00.02/2019 pada tanggal 24 Juni 2019.

\section{Hasil Penelitian}

Tabel 1. Proporsi Sosial Ekonomi Ibu Melahirkan SC di RSP Rujukan Periode Januari-Desember 2018

\begin{tabular}{|c|c|c|c|}
\hline \multirow{2}{*}{$\begin{array}{c}\text { Variabel } \\
\text { Sosial Ekonomis }\end{array}$} & & \multicolumn{2}{|c|}{$\mathrm{N}=385$} \\
\hline & & $\mathbf{n}$ & $\%$ \\
\hline \multirow[t]{4}{*}{ Jenis Jaminan } & JKN & 304 & 79 \\
\hline & PBI & 15 & 3.9 \\
\hline & Non PBI & 289 & 75.1 \\
\hline & Non JKN & 81 & 21 \\
\hline \multirow[t]{4}{*}{ Kelas Rawat } & Non Kelas 3 & 323 & 83.9 \\
\hline & Kelas 2 & 200 & 51.9 \\
\hline & Kelas1\&VIP & 123 & 31.9 \\
\hline & Kelas 3 & 62 & 16.1 \\
\hline \multirow[t]{2}{*}{ Jenis Rujukan } & Puskesmas & 163 & 42.3 \\
\hline & Non Puskesmas & 222 & 57.7 \\
\hline \multirow[t]{6}{*}{ Pendidikan } & SD & 4 & 1 \\
\hline & SMP & 32 & 8.3 \\
\hline & SMA & 182 & 47.3 \\
\hline & D3 & 48 & 12.5 \\
\hline & S1 & 114 & 29.6 \\
\hline & S2 & 5 & 1.3 \\
\hline \multirow[t]{6}{*}{ Pekerjaan } & IRT & 221 & 57.4 \\
\hline & Wirausaha & 16 & 4.2 \\
\hline & Kary.Swasta & 112 & 29.1 \\
\hline & PNS & 13 & 3.4 \\
\hline & Dokter & 9 & 2.3 \\
\hline & Perawat & 14 & 3.6 \\
\hline \multirow[t]{7}{*}{ Suku } & Jawa & 129 & 33.5 \\
\hline & Sunda & 47 & 12.2 \\
\hline & Padang & 27 & 7 \\
\hline & Batak & 14 & 3.6 \\
\hline & Manado & 5 & 1.3 \\
\hline & Betawi & 148 & 38.4 \\
\hline & Lain lain & 15 & 3.9 \\
\hline
\end{tabular}

Hasil penelitian menunjukan proporsi ibu melahirkan SC di RSP X sebesar 71,29\% dari total 742 persalinan. Sebesar 79\% nya adalah peserta JKN dengan jenis kepersertaan Penerima Bantuan Iuran (PBI) sebesar hanya 3,9\%. Kelas rawat kelas 2 (51,9\%) menjadi pilihan ibu melahirkan SC di RSP X. Sebagian besar ibu melahirkan SC $(57,7 \%)$ bukan rujukan dari Puskesmas (Non Puskesmas). Ibu melahirkan SC paling banyak berpendidikan SMA (47,3\%) dan Ibu Rumah Tangga $(57,4 \%)$.

Secara Klinis jenis SC yang terbanyak adalah SC elektif $(63,9 \%)$, pada usia ibu $21-34$ tahun(78,4\%) dengan usia kehamilan antara 37-40 minggu $(92,7 \%)$. Ibu yang sudah memiliki satu anak/primipara $(88,1 \%)$ merupakan kelompok terbanyak dilakukan tindakan SC dengan riwayat ANC di dalam RS (99.7\%). Kondisi panggul Ibu kebanyakan tidak diketahui (92.2\%) atau 
Tabel 2. Proporsi Klinis Ibu melahirkan SC di RSP Rujukan Periode Januari-Desember 2018

\begin{tabular}{|c|c|c|c|}
\hline \multirow{2}{*}{$\begin{array}{c}\text { Variabel } \\
\text { Klinis }\end{array}$} & & \multicolumn{2}{|c|}{$\mathrm{N}=385$} \\
\hline & & $\mathbf{n}$ & $\%$ \\
\hline \multirow[t]{2}{*}{ Jenis SC } & Elektif & 246 & 63.9 \\
\hline & Cito & 139 & 36.1 \\
\hline \multirow[t]{2}{*}{ Usia Ibu } & 21 thn -34 thn & 302 & 78.4 \\
\hline & $\leq 20 \& \geq 35$ thn & 83 & 21.6 \\
\hline \multirow[t]{2}{*}{ Kehamilan } & 37-40 minggu & 357 & 92.7 \\
\hline & $<37 \mathrm{mg} \&>40 \mathrm{mg}$ & 28 & 7.3 \\
\hline \multirow[t]{2}{*}{ Paritas } & Primipara & 339 & 88.1 \\
\hline & Multipara & 46 & 11.9 \\
\hline \multirow[t]{2}{*}{ ANC } & ANC di luar RS & 1 & 0.3 \\
\hline & ANC di dalam RS & 384 & 99.7 \\
\hline \multirow[t]{2}{*}{ Pelvic } & Tercatat & 7 & 1.8 \\
\hline & Tidak tercatat & 378 & 98.2 \\
\hline \multirow[t]{2}{*}{ Plasenta } & Normal & 17 & 4.4 \\
\hline & Previa Totalis & 368 & 95.6 \\
\hline Penyakit & Ada penyerta & 139 & 36.1 \\
\hline \multirow[t]{12}{*}{ Penyerta } & Hipertensi & 7 & 1.8 \\
\hline & $\mathrm{Dm}$ & 2 & 0.5 \\
\hline & Vertigo & 1 & 0.3 \\
\hline & Anemia & 11 & 2.9 \\
\hline & Asma & 16 & 4.2 \\
\hline & Peb & 13 & 3.4 \\
\hline & Haemoroid & 1 & 0.3 \\
\hline & Hbs ag+ & 3 & 0.8 \\
\hline & Kpd & 73 & 19.0 \\
\hline & Tumor vulva & 2 & 0.5 \\
\hline & Oligohidramnion & 10 & 2.6 \\
\hline & Tanpa penyerta & 246 & 63.9 \\
\hline \multirow[t]{2}{*}{ Posisi Bayi } & Sunsang & 17 & 4.4 \\
\hline & Oblih & 368 & 95.6 \\
\hline
\end{tabular}

tidak tercatat di rekam medis. Kondisi ibu melahirkan SC dengan plasenta previa totalis $(95,6 \%)$ lebih banyak dari plasenta normal. Ibu tanpa penyakit penyerta $(63,9 \%)$ lebih banyak dilakukan tindakan SC. Posisi Janin lebih banyak dalam keadaan Oblih yaitu posisi janin di rahim dengan keadaan miring atau melintang dari jalan keluar saat bayi akan dilahirkan (95,6\%).

Tabel 3 menjelaskan hasil uji statistik bivariat menunjukan bahwa terdapat perbedaan yang signifikan antara ibu melahirkan SC rujukan non puskesmas dan puskesmas terhadap jenis jaminan. Ibu melahirkan SC rujukan non puskesmas $(\mathrm{OR}=2,320)$ cenderung 2,320 kali lipat menggunakan JKN dibandingkan ibu melahirkan SC rujukan dari puskesmas.

Tabel 4 adalah hasil uji statistik bivariat menunjukkan terdapat hubungan yang signifikan antara usia ibu ( $p=0,010)$, kondisi plasenta $(p=0,029)$ dan penyakit penyerta $(\mathrm{p}=0,001)$ pada ibu melahirkan $\mathrm{SC}$ dengan jenis jaminan kesehatan. Usia ibu melahirkan SC yang berusia 21-34 tahun (OR=2,574) cenderung 2,574 kali lipat menggunakan JKN dibandingkan ibu dengan usia $\leq 20$ dan $\geq 35$ tahun. Kondisi plasenta previa totalis $(O R=1,282)$ pada ibu melahirkan $S C$ cenderung 1,282 kali lipat menggunakan JKN dibandingkan kondisi plasenta previa totalis. Ibu melahirkan SC tanpa penyakit penyerta $(\mathrm{OR}=2,761)$ cenderung 2,761 kali lipatnya menggunakan JKN dibandingkan ibu tanpa penyakit penyerta.

Tabel 5 hasil analisa regresi logistik menunjukkan rujukan $(p=0,003)$, usia Ibu $(p=0,010)$ dan penyakit penyerta $(p=0,001)$ pada ibu melahirkan SC dalam penggunaan Jaminan Kesehatan. Ibu melahirkan SC rujukan puskesmas $(\mathrm{OR}=2,338)$ cenderung menggunakan JKN 2,338 kali lipat dibandingkan rujukan dari non puskesmas. Ibu melahirkan SC yang berusia 21 -34 tahun(OR=2,691) cenderung 2,691 kali lipat menggunakan JKN daripada ibu melahirkan SC yang berusia $\leq 20$ dan $\geq 35$ tahun dan Ibu melahirkan SC tanpa penyakit penyerta (OR= 2,783 ) cenderung 2,783 kali lipat menggunakan JKN dibandingkan yang dengan ibu dengan penyakit penyerta.

Tabel 3. Proporsi Karakteristik Sosial Ekonomi Ibu Melahirkan SC Berdasarkan Jaminan Kesehatan di RSP Rujukan Periode Januari-Desember 2018

\begin{tabular}{|c|c|c|c|c|c|c|c|}
\hline \multirow{2}{*}{\multicolumn{2}{|c|}{$\begin{array}{l}\text { Variabel } \\
\text { Sosial Ekonomis }\end{array}$}} & \multicolumn{4}{|c|}{ Jaminan } & \multirow{3}{*}{$\begin{array}{c}\text { Chi Square } \\
\text { p }\end{array}$} & \multirow{3}{*}{ OR } \\
\hline & & \multicolumn{2}{|c|}{ JKN (n=304) } & \multicolumn{2}{|c|}{ Non JKN(n=81) } & & \\
\hline & & $\mathbf{N}$ & $\%$ & $\mathbf{N}$ & $\%$ & & \\
\hline \multirow[t]{2}{*}{ Kelas } & Non Kelas 3 & 260 & 80.5 & 63 & 19.5 & 0.092 & 1.688 \\
\hline & Kelas 3 & 44 & 71 & 18 & 29 & & $(0.914-3.118)$ \\
\hline \multirow[t]{3}{*}{ Rujukan } & Non & 222 & 86.5 & 22 & 13.5 & 0.002 & 2.320 \\
\hline & Puskesmas & & & & & & $(1.353-3.977)$ \\
\hline & Puskesmas & 163 & 73.4 & 59 & 26.6 & & \\
\hline \multirow[t]{2}{*}{ Pendidikan } & $=\mathrm{SMP}$ & 26 & 72.2 & 10 & 27.8 & 0.297 & 0.664 \\
\hline & $>$ SMP & 278 & 79.7 & 71 & 20.3 & & $(0.306-1.441)$ \\
\hline \multirow[t]{2}{*}{ Pekerjaan } & Tidak bekerja & 173 & 78.3 & 48 & 21.7 & 0.704 & 0.908 \\
\hline & Bekerja & 131 & 79.9 & 33 & 20.1 & & $(0.552-1.494)$ \\
\hline \multirow[t]{2}{*}{ Suku } & Jawa & 106 & 82.2 & 23 & 17.8 & 0.273 & 1.350 \\
\hline & Non Jawa & 198 & 77.3 & 58 & 22.7 & & $(0.789-2.311)$ \\
\hline
\end{tabular}


Tabel 4. Proporsi Karakteristik Klinis Ibu Melahirkan SC berdasarkan Jaminan Kesehatan di RSP Periode JanuariDesember 2018

\begin{tabular}{|c|c|c|c|c|c|c|c|}
\hline \multirow{2}{*}{\multicolumn{2}{|c|}{$\begin{array}{l}\text { Variabel } \\
\text { Klinis }\end{array}$}} & \multicolumn{4}{|c|}{ Jaminan } & \multirow{3}{*}{$\begin{array}{c}\text { Chi Square } \\
\text { p }\end{array}$} & \multirow{3}{*}{$\begin{array}{c}\text { 95\%CI } \\
\text { OR }\end{array}$} \\
\hline & & \multicolumn{2}{|c|}{ JKN } & \multicolumn{2}{|c|}{ Non JKN } & & \\
\hline & & $\mathbf{N}$ & $\%$ & $\mathbf{N}$ & $\%$ & & \\
\hline \multirow[t]{2}{*}{ Jenis SC } & Cyto & 110 & 79.1 & 29 & 35.8 & 0.949 & 1.017 \\
\hline & Elektif & 194 & 78.9 & 52 & 64.2 & & $(0.610-1.695)$ \\
\hline \multirow[t]{2}{*}{ Usia Ibu } & 21 thn -34 thn & 230 & 76.2 & 72 & 23.8 & 0.010 & 2.574 \\
\hline & $=20 \&=35$ thn & 74 & 89.2 & 9 & 10.8 & & $(1.227-5.399)$ \\
\hline \multirow[t]{2}{*}{ Kehamilan } & 37-40 minggu & 282 & 79 & 75 & 21 & 0.958 & 1.025 \\
\hline & $<37 \mathrm{mg}>40 \mathrm{mg}$ & 22 & 78.6 & 6 & 21.4 & & $(0.40-2.620)$ \\
\hline \multirow[t]{2}{*}{ Paritas } & Primipara & 271 & 79.9 & 68 & 20.1 & 0.200 & 1.570 \\
\hline & Multipara & 33 & 71.7 & 13 & 28.3 & & $(0.784-3.145)$ \\
\hline \multirow[t]{2}{*}{ ANC } & ANC luar RS & 1 & 100 & 0 & 0 & 0.605 & 1.267 \\
\hline & ANC dalam RS & 303 & 78.9 & 81 & 21.1 & & (1.203-1.335) \\
\hline \multirow[t]{2}{*}{ Konisi Panggul } & Tercatat & 7 & 100 & 0 & 0 & 0.168 & 1.273 \\
\hline & Tidak tercatat & 297 & 78.6 & 81 & 21.4 & & $(1.207-1.342)$ \\
\hline \multirow[t]{2}{*}{ Plasenta } & Previa Totalis & 287 & 78.0 & 81 & 22 & 0.029 & 1.282 \\
\hline & Normal & 17 & 100.0 & 0 & 0 & & (1.214-1.354) \\
\hline \multirow[t]{2}{*}{ Penyerta } & Tanpa Penyerta & 181 & 73.6 & 65 & 26.4 & 0.001 & 2.761 \\
\hline & Ada penyerta & 123 & 88.5 & 16 & 11.5 & & $(1.526-4.995)$ \\
\hline \multirow[t]{2}{*}{ Posisi Bayi } & Sunsang & 13 & 76.5 & 4 & 23.5 & 0.69 & 0.791 \\
\hline & Oblih & 291 & 79.1 & 77 & 20.9 & & $(0.248-2.521)$ \\
\hline
\end{tabular}

Tabel 5. Model Akhir Multivariat Karakter Sosial Ekonomi dan Klinis Ibu Melahirkan SC Dengan Jaminan Kesehatan RSP X

\begin{tabular}{lcccc}
\hline Variabel & & & \multicolumn{2}{c}{ 95\% C.I. } \\
\cline { 3 - 5 } & $\mathbf{p}$ & $\operatorname{Exp(B)}$ & Lower & Upper \\
\hline Rujukan & 0.003 & 2.338 & 1.347 & 4.059 \\
Usia Ibu & 0.010 & 2.691 & 1.262 & 5.738 \\
Penyakit Penyerta & 0.001 & 2.783 & 1.521 & 5.090 \\
\hline
\end{tabular}

\section{Pembahasan}

Proporsi ibu melahirkan SC di RSP X sebesar $71.29 \%$ dari total 742 persalinan. Sebesar 79\%nya adalah peserta JKN dengan jenis kepersertaan Penerima Bantuan Iuran (PBI) sebesar hanya 3.9\%. PBI adalah peserta Jaminan Kesehatan bagi fakir miskin dan orang tidak mampu sebagaimana diamanatkan Undang Undang (UU) Sistem Jaminan Sosial Nasional (SJSN) yang diatur dalam UU No. 40 Tahun 2004 dengan berlandaskan UUD 1945, yang iurannya dibayari Pemerintah sebagai peserta program Jaminan Kesehatan. Peserta PBI adalah fakir miskin yang ditetapkan oleh Pemerintah dan diatur melalui Peraturan Pemerintah. Keadaan ini sejalan dengan data BPS wilayah RSP X yaitu hingga bulan maret 2018, jumlah penduduk miskin di wilayah tersebut mencapai 661,36 ribu orang $(5,24 \%)$, berkurang sebanyak 38,47 ribu orang dibandingkan dengan kondisi september 2017 yang sebesar 699,83 ribu orang (5,59\%). Selama periode september 2017 - maret 2018, jumlah penduduk miskin Banten di daerah perkotaan turun sebanyak 21,87 ribu orang (dari 415,67 ribu orang menjadi 393,80 ribu orang), sementara di daerah perdesaan turun sebanyak 16,61 ribu orang (dari 284,16 ribu orang menjadi 267,55 ribu orang). Secara hitungan capaian nasional Banten merupakan Provinsi dengan kemiskinan terendah ke 4 se Indonesia. ${ }^{6}$

Ibu melahirkan SC rujukan Non puskesmas $(\mathrm{OR}=2.320$ ) cenderung 2.320 kali lipat menggunakan JKN dibandingkan ibu melahirkan SC rujukan dari puskesmas. Dengan kata lain ibu melahirkan SC rujukan Non Puskesmas cenderung lebih banyak yang menggunakan JKN. Hal ini dapat saja terjadi karena kegawatdarurat ibu melahirkan SC yang harus segera dibawa langsung ke RS terdekat tanpa melewati PPK 1 tapi langsung dibawa ke rumah sakit yang merupakan Fasilitas Kesehatan Rujukan Tingkat Lanjut (FKRTL) terdekat. Namun keadaan ini bertolak belakang dengan proporsi SC elektif $(63,9 \%)$ lebih banyak daripada SC Cito. Berdasarkan tingkat urgensinya SC dapat dibedakan menjadi SC Cito dan Elektif. SC Cito yaitu SC yang dilakukan setelah proses pesalinan dimulai. Hanya $1 \%$ kehamilan yang memerlukan SC Cito. Sedangkan SC elektif adalah tindakan SC terencana yang dilakukan sebelum proses persalinan dimulai. ${ }^{7}$ Tindakan SC dilakukan secara elektif ataupun emergensi berdasarkan kategori tingkat urgensinya. Studi menunjukkan bahwa melakukan SC dengan indikasi 
secara terencana memberikan dampak lebih baik secara psikologis terhadap ibu. Meskipun demikian, segala upaya untuk mencegah SC perlu dilakukan sebelum melakukan tindakan SC bila memungkinkan. . $^{8,9}, 10,11$

Dalam JKN Ibu melahirkan SC yang dirujuk dari Puskesmas sesuai aturan kewenangan klinis Pemberi Pelayanan Kesehatan I (PPK) bahwa Puskesmas tidak memiliki kewenangan melakukan tindakan SC sehingga digolongkan dalam indikasi rujuk. Namun demikian kualitas indikasi rujuk oleh tenaga kesehatan perlu dievaluasi kembali untuk dapat melihat efektivitas kualitas rujukan. Sejalan pada penelitian Astoguno dkk (2016) yang menyatakan distribusi persalinan dengan menggunakan program JKN-BPJS paling sedikit ditemukan pada ibu hamil yang masuk rumah sakit dengan dirujuk oleh puskesmas yaitu 21 kasus (5\%) dan terbanyak pada ibu hamil yang masuk rumah sakit dengan cara datang sendiri, yaitu 188 kasus $(44,5 \%){ }^{12}$ Demikian pula penelitian yang dilakukan oleh Dinas Kesehatan Provinsi DKI Jakarta bekerja sama dengan Fakultas Kedokteran Universitas Gadjah Mada (2014) menemukan adanya permintaan rujukan yang berasal dari pasien sendiri. Seringkali keluarga pasien (perempuan) peserta JKN-BPJSK datang ke puskesmas hanya untuk meminta surat rujukan agar bisa mengakses dan memanfaatkan pelayanan kesehatan di fasilitas kesehatan yang lebih mudah mereka akses ataau lebih dekat dari rumahnya. ${ }^{13}$

Penelitian ini menunjukan klinis Ibu melahirkan SC usia 21-34 tahun (OR=2.574) cenderung 2.574 kali lipat menggunakan JKN dibandingkan ibu dengan usia d" 20 dan e" 35 tahun.Hal ini tentunya bertolak belakang dengan pernyataan usia ibu melahirkan d" 20 tahun atau e" 35 tahun) lebih berisiko terhadap tindakan SC dibandingkan dengan ibu yang berusia 21-34 tahun. Panggul dan rahim pada ibu dengan usia usia d" 20 belum berkembang dengan baik sehingga dapat menjadi penyulit persalinan. Selain itu risiko kematian pada wanita usia 35 tahun juga 3 kali lebih tinggi dari kelompok usia reproduksi sehat (2135 tahun). ${ }^{14}$

Penelitian Sihombing (2017) dari data Riset Kesehatan Dasar (Riskesdas) tahun 2013 menyatakan bahwa ibu diatas usia 35 tahun 1,68 kali lebih cenderung untuk terjadinya persalinan SC dibandingkan ibu yang dengan persalinan di rentang usia 20-35 tahun ${ }^{15}$. Hasil penelitian Pratiwi (2019) menunjukan pasien yang membayar melalui BPJSK/Jampersal 4,417 kali lebih mungkin untuk mengambil keputusan bersalin melalui $\mathrm{SC}$, dengan gambaran klinis ibu melahirkan SC pasien yang berusia d" 20 dan e" 35 tahun memiliki risiko 4,617 kali untuk melahirkan melalui SC dibandingkan dengan pasien yang berusia 21-34 tahun $(\mathrm{p}<0,05) .{ }^{16}$

Ibu melahirkan SC tanpa penyakit penyerta $(\mathrm{OR}=2,761)$ cenderung 2,761 kali lipatnya menggunakan JKN dibandingkan ibu dengan penyakit penyerta. Hal ini berbeda dengan hasil penelitian Andayasari dkk (2015) yang menyatakan penyakit penyerta merupakan faktor yang berhubungan untuk terjadinya persalinan SC di rumah sakit tersebut. ${ }^{17}$ Hipertensi merupakan salah satu penyakit penyerta untuk dilakukan SC baik elektif maupun emergensi. Hipertensi memiliki risiko 3 kali dibandingkan dengan yang tidak hipertensi. Kemudian ibu dengan indikasi hipertensi berisiko 7 kali lebih besar untuk dilakukan persalinan SC secara emergensi dibandingkan dengan ibu tanpa hipertensi.

Penelitian Media dkk (2019) tentang implementasi program JKN dan permasalahannya dalam penurunan angka kematian ibu di kabupaten solok, provinsi sumatera barat menyatakan kematian ibu disebabkan disebabkan karena adanya penyakit penyerta seperti Hipertensi Dalam Kehamilan (HDK) dan kelainan jantung ${ }^{18}$. Sebagian masyarakat cenderung melakukan pemeriksaan kehamilan setelah memasuki usia kehamilan 5 atau bulan 6 bulan, sehingga sebagian masyarakat tidak bisa melakukan pemeriksaan kehamilan yang sesuai standar kesehatan (minimal 4 kali). Pada hal ANC yang berkualitas atau pelayanan pemeriksaan kehamilan yang dilakukan secara teratur oleh tenaga kesehatan (minimal 4 kali) diharapkan dapat menurunkan angka kematian ibu. Dengan upaya ini diharapkan komplikasi atau penyakit dapat dideteksi lebih dini dan dapat ditangani secara cepatKeadaan ini biasanya menyebabkan penanganan kelahiran dengan SC terpaksa dilakukan. Penelitian di Amerika dan Jerman menunjukkan bahwa persalinan SC meningkat pada ibu dengan penyakit penyerta kronis seperti jantung, ASMA dan Diabetes. ${ }^{19}$

Data - data tersebut memungkinkan untuk dijadikan alasan tingginya persalinan dengan SC dengan menggunakan JKN-BPJS. Data yang didapat dari BPJS tahun 2017 pembiayaan tertinggi mencapai 2,247 triliun rupiah di bayarkan untuk tindakan Sectio Caesaria. ${ }^{20}$ Di era JKN diharapkan para praktisioner seperti dokter di berbagai tingkat layanan kesehatan dapat turut serta mendorong ibu dan keluarga untuk memahami betul proses persalinan beserta risiko risiko penyertanya, sehingga kepemilikan jaminan kesehatan tidak mendorong terjadinya peningkatan trend persalinan SC di Indonesia. Hal ini tentunya sejalan dengan tujuan kepersertaan JKN bahwa pelayanan yang diberikan perlu memperhatikan kendali mutu dan kendali biaya. 


\section{Kesimpulan}

Ibu melahirkan SC di RSPX sebesar 79\% adalah pengguna JKN. Ibu melahirkan SC cenderung 2.320 kali lipat rujukan dari Non Puskesmas dengan kelompok usia ibu 21-34 tahun cenderung 2.574 kali lipat dibandingkan kelompok usia d" 20 \& e" 35thn dan ibu dengan kondisi plasenta previa totalis cenderung 1.273 lebih banyak dari plasenta normal serta tanpa penyakit penyerta 2.761 kali lipat berpeluang untuk menggunakan JKN.

\section{Daftar Pustaka}

1.Budi Hidayat. 2019. Keberlangsungan Program JKN dalam SJSN. Komisi IX DPR RI

2.Muljati. 2014. Faktor yang berhubungan dengan Sectio Caesarea di Jakarta. (Http//3A\%2F\%2Fejournal. Diakses pada tanggal 20 April 2018).

3.World Health Organization. WHO Statement on Caesarean Section Rates. Human Reproductive Program. 2015;23:14950.

4.Survei Demografi Dan Kesehatan (SDKI) 2017

5.Balitbangkes. (2013). Riset Kesehatan Dasar. Laporan Nasional Badan Penelitian dan Pengembangan Kesehatan, Kementerian Kesehatan Republik Indonesia. Jakarta. Kemenkes RI.

6.Profil Kemiskinan di Banten Maret 2018/Berita Resmi Statistik No. 39/07/36/Th.XII, 16 Juli 2018). (http:// www.tangerangtribun.com/angka-kemiskinan-di-bantenmenurun-begini-penjelasan-bps/

7.NICE Clin Guidel. 2011;282. Royal College of Obstetricions and Gynaecologists. Caesarean Section Guidelines.

8.Johnson A, Tough S. 2012.Delayed ChildBearing. J Obstet Gynaecol Can. 2012;34 (1):81.)

9.Cunningham F, Leveno K, Bloom S, Spong C, Dashe J, Hoffman B, et al. 2011. Cesarean delivery and peripartum hysterectomy. In: William's Obstetrics. 24th ed. New York: Mc Graw HIl; 2011. p. 587-607.

10.Handelzalts JE, Waldman Peyser A, Krissi H, Levy S, Wiznitzer A, Peled Y. Indications for emergency intervention, mode of delivery, and the childbirth experience. PLoS One. $2017 ; 12$.
11.Mylonas I, Friese K. Indications for and Risks of Elective Cesarean Section. Dtsch Arztebl Int. 2015;112:48995.Henderson-smart DJ, Lumbiganon P, Festin MR, Ho JJ, Mohammad H, Mcdonald SJ, et al. Methodology Optimising reproductive and child health outcomes by building evidencebased research and practice in South East Asia ( SEA-ORCHID ): study protocol. BMC Med Res Methodol [Internet]. 2007;7(43):1-9.

12.Arya P. Astoguno, Joice J Kaeng, Maya Mewengkang.2016. Jurnal e-Clinic (eCl), Volume 4, Nomor 2, Juli-Desember 2016 Profil persalinan pada era JKN-BPJS di RSUP Prof Dr. R. D. Kandou Manado periode 1 Januari - 30 Juni 2016.

13.DKI Jakarta. 2014. Seminar Sistem dan Pedoman Rujukan Layanan Kesehatan Primer di Provinsi DKI Jakarta. Diakses pada 3 Januari, 2015, from http://sistemrujukanpuskesmas-dki.net/index.php/2- uncategorised/38seminar-sistemdanpedoman-rujukan-layanankesehatanprimer-di-provinsi-dkijakarta

14.Kementrian Kesehatan RI. 2010. Pedoman Pemantauan Wilayah Setempat Kesehatan Ibu Dan Anak (PWSKIA). Jakarta; 2010

15.Sihombing, N., Saptarini, I. \& Putri, D.S.K., 2017. Determinan Persalinan Sectio Caesarea di Indonesia (Analisis Lanjut Data Riskesdas 2013). Jurnal Kesehatan Reproduksi, 8(1), pp.63-75.

16.Regina A B Pratiwi*, Rimonta F. Gunanegara**, July Ivone $^{* * *} .2019$. Journal of Medicine and Health Factors Affecting Caesarean Labor... Vol2 No.3 February 2019 Faktor - Faktor yang Memengaruhi Persalinan dengan Sectio Caesarea di RSUD Lembang pada tahun 2017

17.Lelly Andayasari;* Sri Muljati; Marice Sihombing; Dona Arlinda; Cicih Opitasari; Danny Fajar Mogsa; Widianto. 2015. Proporsi Seksio Sesarea Dan Faktor Yang Berhubungan Dengan Seksio Sesarea Di Jakarta The Proportion Of Caesarean Section And Associated Factors In Hospital Of Jakarta Buletin Penelitian Kesehatan, Vol. 43, No. 2, Juni 2015 : 105 - 116 .

18.Yulfira Media. 2019. Implementasi Program Jaminan Kesehatan Nasional Dan Permasalahannya Dalam Penurunan Angka Kematian Ibu (Studi Di Kabupaten Solok, Provinsi Sumatera Barat) . Badan Penelitian Dan Pengembangan Provinsi Sumatera Barat

19.Rasjidi, Imam. 2009. Manual Seksio Sesarea \& Laparotomi Kelainan Adneksa. Jakarta: CV Sagung Seto.

20.BPJS Kesehatan. Seputar BPJS Kesehatan, 2013:46. Cited 2018 April 3]. 